\section{Opioid-free anesthesia works like a charm in cardiac surgery}

TO THE EDITOR: The progress of contemporary perioperative medicine is accompanied by increasing questioning in current clinical practice. One of these questions is regarding the use of routine perioperative opioids. For many years, opioid-based anesthesia has been the cornerstone of analgesia management in both intraoperative and postoperative periods. High-dose opioid induction and maintenance, a technique that dates as far back as the 1980s, has been deemed the gold standard for cardiac surgery patients. However, over time, it became clear that high-dose opioid regimens were associated with side effects such as prolonged mechanical ventilation, increased length of stay in the intensive care unit (ICU) or hospital, impaired gastrointestinal function, postoperative nausea and vomiting, pruritus, urinary retention, delirium, and the potential development of opioid addiction [1]. Before the 2000s, a recommendation to 'fast track' after cardiac surgery was proposed [2]. Accordingly, there have been changes in the technique, and balanced anesthesia has become more preferred. Smaller doses of short-acting opioids, non-opioid analgesics, adjuvant drugs, regional blocks, and inhalational anesthetic agents were used in patients. With the fast track method, it was shown that the durations of mechanical ventilation, intensive care, and hospital stay were shortened, and cost was reduced. Therefore, the technique has become an obvious advantage [3]. Acute tolerance and hyperalgesia caused by opioids serve as an incentive for opioid use in the perioperative period. This is followed by an increased risk of addiction. All of these disadvantages became apparent over time, and doctors turned to less-opioid or opioid-free anesthesia techniques to overcome these problems. Opioid-free anesthesia (OFA) is a technique in which non-opioid multimodal analgesics are used to provide adequate pain control during the perioperative period [4]. There are many alternative non-opioid analgesic drugs with lower dependency potentials and better side effect profiles for the application of OFA. In the OFA protocol used in our clinic, many non-opioid analgesic drug combinations were applied over the long time interval between the preoperative period and discharge. The night before the operation, the patient is administered a pregabalin $150 \mathrm{mg}$ oral tablet. In addition, $0.25 \mu \mathrm{g} / \mathrm{kg}$ i.v. dexmedetomidine is administered for 10 min during the preoperative period. A $50 \mathrm{ml}$ solution containing $50 \mu$ g dexmedetomidine, $50 \mathrm{mg}$ ketamine, and 500 $\mathrm{mg}$ lidocaine is prepared. Immediately before anesthesia induction, $1 \mathrm{ml} / 10 \mathrm{~kg} / 10 \mathrm{~min}$ infusion of the solutions administered. Anesthesia is then induced with propofol and rocuronium. Fifty milligrams of ketamine is added before surgery. For anesthesia maintenance, the solution is continued throughout the operation by reducing the dose to 1 $\mathrm{ml} / 10 \mathrm{~kg} / \mathrm{h}$, and a volatile agent is administered according to the bispectral index (BIS) value. Additionally, $1.5 \mathrm{mg}$ of magnesium is administered before cardiopulmonary bypass (CPB) and $1 \mathrm{~g}$ of paracetamol is administered during sternum closing. Infiltration anesthesia is administered with $10 \mathrm{ml}$ of $0.25 \%$ bupivacaine in the chest drain regions. At the end of the operation, the solution dose is reduced to $0.5 \mathrm{ml} / 10 \mathrm{~kg} / \mathrm{h}$ and continued until extubation in the postoperative period. Paracetamol ( $1 \mathrm{~g})$ is administered every 6-8 $\mathrm{h}$ for the first $24 \mathrm{~h}$. If the visual analog score is over 4 points, tramadol hydrochloride $1 \mathrm{mg} / \mathrm{kg}$ is administered as a rescuer therapy. The patients are extubated within $2-3 \mathrm{~h}$. Non-steroidal anti-inflammatory analgesic drugs are not suitable for cardiac surgery because of their prothrombotic effects [5]. Therefore, they are not included in the OFA protocol. The erector spina-plane block is also added preoperatively to this defined protocol according to the patient's request. We would like to present three cases in which our OFA protocol was used. The necessary patient and publication consent has been obtained.

The first case involved a 43-year-old woman scheduled for beating heart coronary surgery. The second case involved a 49-year-old man who underwent coronary artery bypass graft surgery with CPB. The third case involved a 49-year-old woman who was scheduled for mitral valve replacement (MVR) with CPB. The patients had an average adult weight and no history of any disease. However, the patient scheduled for MVR had atrial fibrillation. Accord-

This is an Open Access article distributed under the terms of the Creative Commons Attribution Non-Commercial License (http://creativecommons.org/licenses/by-nc/4.0) which permits unrestricted non-commercial use, distribution, and reproduction in any medium, provided the original work is properly cited.

Copyright (C) the Korean Society of Anesthesiologists, 2021 
ing to the OFA protocol, $0.25 \mu \mathrm{g} / \mathrm{kg}$ intravenous dexmedetomidine was administered for $10 \mathrm{~min}$ in the preoperative period. A $50 \mathrm{ml}$ solution containing $50 \mu \mathrm{g}$ dexmedetomidine, $50 \mathrm{mg}$ ketamine, and $500 \mathrm{mg}$ lidocaine was prepared. Just before induction, a $1 \mathrm{ml} / 10 \mathrm{~kg} / 10 \mathrm{~min}$ infusion was administered with this solution. Anesthesia was induced with propofol and rocuronium. For maintenance, this solution was continued throughout the operation by reducing the dose to $1 \mathrm{ml} / 10 \mathrm{~kg} / \mathrm{h}$. The sevoflurane concentration was set as the target BIS (40-50). Just before the surgery, 50 mg ketamine was added. Additionally, $1.5 \mathrm{~g}$ magnesium was administered before CPB. Paracetamol ( $1 \mathrm{~g})$ was administered during sternal closure. Infiltration anesthesia was performed with $10 \mathrm{ml}$ of $0.25 \%$ bupivacaine in the chest drain regions. At the end of the operation, the solution dose was reduced to $0.5 \mathrm{ml} / 10 \mathrm{~kg} / \mathrm{h}$ and continued until extubation. Paracetamol ( $1 \mathrm{~g}$ ) was administered every 6-8 $\mathrm{h}$ for the first $24 \mathrm{~h}$. Only the 2 nd patient needed additional tramadol once. The patients were extubated after 2-3 $\mathrm{h}$ and did not have any significant side effects. The patients were successfully discharged from the ICU the next day and from the hospital on postoperative day 6. Intubation time, ICU stay, and hospital stay were shorter with the non-opioid regimen than in routine cases, in which patients are extubated after $6-8 \mathrm{~h}$, stay in the ICU for 1-2 days, and stay in the hospital for 7-10 days.

Cardiac surgery patients experience pain in many places, including vascular access sites and saphenous graft harvest sites, and due to sternotomy and drainage tubes. If effective pain control is not achieved in cardiac surgery patients, sympathetic activation may result in unstable hemodynamics and an increased demand for oxygen. This is undesirable in cardiac patients with limited reserves. Therefore, opioid analgesia has been used for many years. However, there is no evidence that quality and effective analgesia can be achieved without opioids [6]. In routine cases at our institution, intraoperative fentanyl consumption per patient in an operation lasting an average of $5 \mathrm{~h}$ is approximately 3 $\mathrm{mg}$. An additional $0.5-1 \mathrm{mg}$ of fentanyl may be used during the ICU and hospital stay. In a case where no opioids are used compared to a case where $4 \mathrm{mg}$ of fentanyl is used, 8 ampoules of fentanyl $(10 \mathrm{ml})$ are saved.

To the best of our knowledge, there are no reports regarding the application of OFA in Turkey, and this report of our experience implementing this protocol is the first. Our cases show that the OFA technique can adequately control pain, reduce opioid requirement, and provide effective he- modynamic stability during cardiac surgery.

$$
\begin{array}{r}
\text { Aysegul Ozgok and Aslı Z Demir } \\
\text { Department of Anaesthesiology, University of Health Sciences, } \\
\text { Ankara City Hospital, Ankara, Turkey }
\end{array}
$$

Corresponding author: Aslı Z Demir, M.D.

Department of Anaesthesiology, University of Health Sciences, Ankara City Hospital, Üniversiteler Mahallesi, Dumlupinar Bulvari No:1, 06800 Çankaya, Ankara, Turkey Tel: 90-5052491598, Fax: 90-3125526000

E-mail: ankarasehirhastanesi@hs03.kep.tr

Received February 23, 2021; Revised: March 15, 2021; Accepted: March 15, 2021 https://doi.org/10.17085/apm.21017

\section{CONFLICTS OF INTEREST}

No potential conflict of interest relevant to this article was reported.

\section{DATA AVAILABILITY STATEMENT}

The datasets generated during and/or analyzed during the current study are available from the corresponding author on reasonable request.

\section{AUTHOR CONTRIBUTIONS}

Conceptualization: Aslı Z Demir. Methodology: Aysegul Ozgok, Aslı Z Demir. Writing - original draft: Aslı Z Demir. Writing -review \& editing: Aysegul Ozgok, Aslı Z Demir. Investigation: Aslı Z Demir.

\section{ORCID}

Aysegul Ozgok, https://orcid.org/0000-0002-0105-3388

Aslı Z Demir, https://orcid.org/0000-0003-3053-0443

\section{REFERENCES}

1. Bohringer C, Astorga C, Liu H. The benefits of opioid free anesthesia and the precautions necessary when employing it. Transl Perioper Pain Med 2020; $7:$ 152-7.

2. Wong WT, Lai VK, Chee YE, Lee A. Fast-track cardiac care for adult cardiac surgical patients. Cochrane Database Syst Rev 2016; 9: CD003587.

3. Myles PS, McIlroy D. Fast-track cardiac anesthesia: choice of anesthetic agents and techniques. Semin Cardiothorac Vasc Anesth 2005; 9: 5-16.

4. Lavand'homme P, Estebe JP. Opioid-free anesthesia: a different regard to anesthesia practice. Curr Opin Anaesthesiol 2018; 31: 55661.

5. Varga Z, Sabzwari SRA, Vargova V. Cardiovascular risk of nonsteroidal anti-inflammatory drugs: an under-recognized public health issue. Cureus 2017; 9: e1144

6. Lavand'homme P. Opioid-free anaesthesia: pro: damned if you don't use opioids during surgery. Eur J Anaesthesiol 2019; 36: 247-9. 